\title{
A Study on Behavioral Characteristics of Track Roadbed according to Steel Pipe Press-in Excavation during Construction of Underground Railway Crossing
}

\author{
Young-Ha Kim, Ki-Young Eum and Jae-Wang Kim ${ }^{\dagger}$
}

\begin{abstract}
In this study, numerical analysis and model experiments were conducted to analyze behavioral characteristics acting on the track roadbed with excavation through steel pipe injection, a non-exclusive method of crossing construction under railroad as primary target. In model experiments that simulate injection excavation behaviors with an increase in the depth of soil cover, the upper displacement was measured by construction of the first and the second pipes in order to predict actual behaviors, and the behavior characteristics were verified through numerical analysis. The investigation results showed that surface displacement was smaller under the condition of higher soil cover. In the case of injecting two pipes, when the first pipe was injected, deformation of the surface increased linearly in both settlement and uplift experiments. However, when the second pipe was injected, the amount of change was found to be very small due to the relaxation and plastic zones around the first pipe. In addition, the results of numerical analysis on the same cross section with the model experiment found that the results of investigation into settlement ratio and volume loss were in very good agreement with those obtained by the model experiment.
\end{abstract}

Keywords : Method of underground railway crossing, Steel pipes press-in excavation, Depth of soil cover, Volume loss, Scale model experiment, Finite element analysis

\section{Introduction}

In recent years, a lot of underground structures have been constructed by crossing the underground railway for the development of rail transport systems, traffic congestion relief and improvement of railway and road safety. The non-excavation method used for underground railway crossing performs construction in a manner that lays pipelines by connecting pipes in order, while digging and taking out earth and sand within the pipes through injection of steel pipes or rectangular pipes in the ground. In general, when pipes are injected in the ground, uplift or settlement occurs in the upper part of the roadbed. The uplift phenomenon occurs in case the driving pressure is greater

\footnotetext{
Corresponding author: High-Speed Railroad Infrastructure Research Team, KRRI, Uiwang 437-757, Korea

E-mail : kjw3091@krri.re.kr

(C)The Korean Society for Railway 2013

http://dx.doi.org/10.7782/IJR.2013.6.2.069
}

than the effects by the release from a tunnel face. On the contrary, settlement phenomenon occurs in case the effects by the release from the tunnel face are greater than the driving pressure. Uplift behaviors occur when excessive driving pressure is generate by the lack of removal of earth and sand within the pipes, contact with obstacles and friction of original clay. In contrast, large amount of settlement occur in case the amount of removed earth and sand is excessive, or deformation of the tunnel face occurs due to the over break. In addition, it frequently occurs due to the subsequent settlement resulting from the contact with obstacles, sediment runoff caused by leakage of groundwater and collapse of the tunnel face.

According to the study of Yoo et al.(2009), the factor that has a direct impact on the soil surface settlement is the depth of soil cover in performing an analysis of GISANN connected underground structures. Yook et al. (2004) conducted a numerical analysis of corrugated steel pipes on the depth of soil cover, and Eum et al.(2010) performed a model experiment on the depth of soil cover 


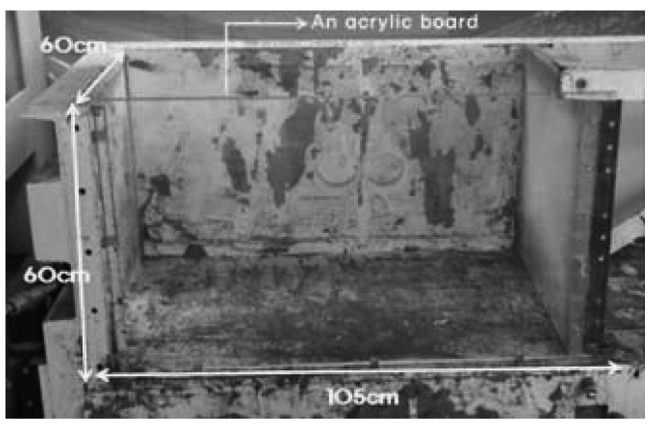

Fig. 1 Calibration chamber test specifications

and degree of compaction of underground crossing structures. According to the research, titled 'Establishment of method standards for underground crossing structures of high-speed railway and stability evaluation', the number of non-excavation methods of underground railway crossing used for construction since 1999 was about 56 cases, and it continues to increase, but there are few researches on the behavioral characteristics of track roadbed or ground according to the steel pipe injection in underground crossing structures.

In this study, we conducted model experiments and numerical analysis for verification to analyze comprehensive behavioral characteristics of track roadbed according to the injection of steel pipes in the ground. Through model experiments, the amount of settlement and uplift as well as behavioral characteristics of the ground in case of injecting steel pipes was analyzed, and the effects according to the depth of soil cover were reviewed respectively. In addition, the same cross section as in the experiments was evaluated numerically. In the numerical analysis, experimental results and the results of numerical analysis were compared and analyzed by modeling the cross section of the model experiments.

\section{Model Experiments}

\subsection{Calibration chamber test and modeling experiment devices}

The circular pipe propulsion experiment device developed in the Korea Railroad Research Institute was used to identify changes in the surface displacement due to the excavation of the inside of the circular pipe. The experiment device consists of three parts such as calibration chamber test, upper displacement system and circular pipe propulsion device.

The calibration chamber test measures $105 \mathrm{~cm} \times 60 \mathrm{~cm}$ $\times 60 \mathrm{~cm}$ (width $\times$ length $\times$ eight) in size as shown in Fig. 1. Its wall and back panels are rigid bodies, and each of the

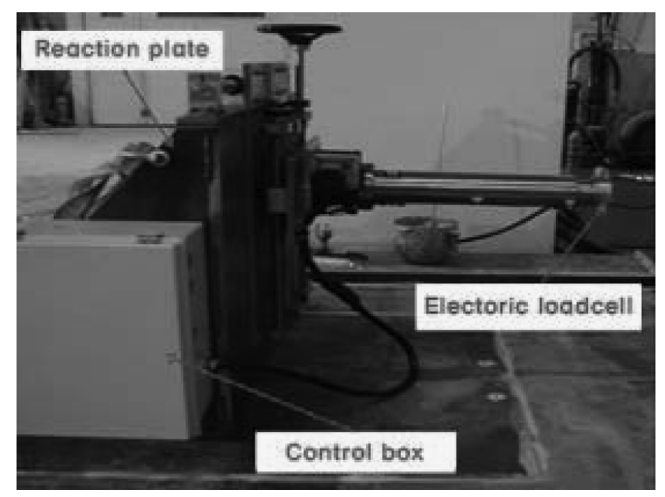

Fig. 2 Circular pipe propulsion device

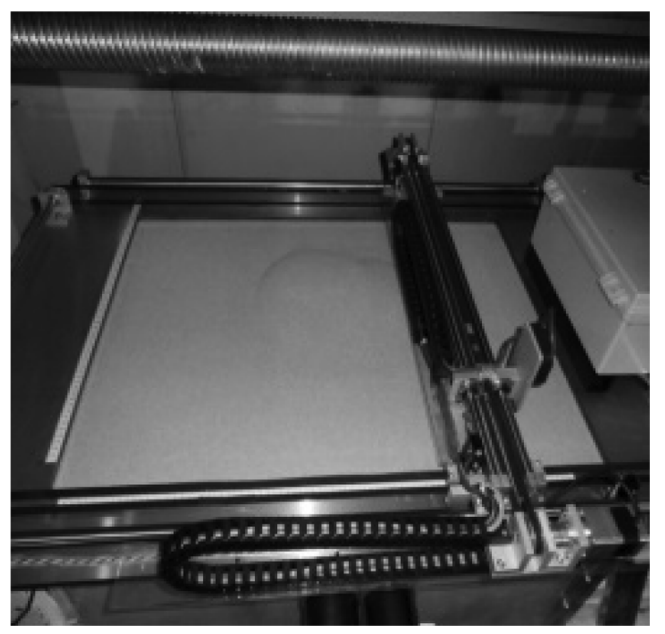

Fig. 3 Laser surface displacement measurement(uplift)

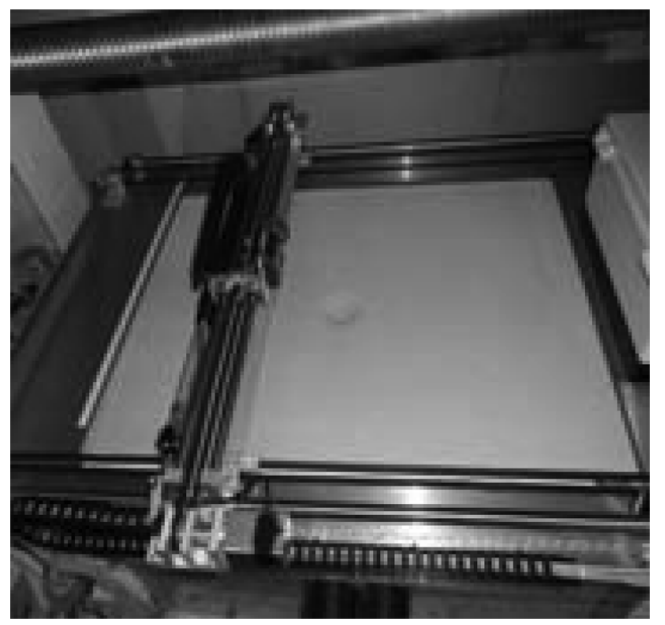

Fig. 4 Laser surface displacement measurement(settlement)

components are fastened by bolts so that displacement due to external loads cannot occur. The ground within the calibration chamber test was created by obtaining the size of 
Table 1 Scale model experiment devices and specifications

\begin{tabular}{|c|c|c|}
\hline \multicolumn{2}{|c|}{ Devices } & Uses and specifications \\
\hline \multirow{2}{*}{$\begin{array}{l}\text { Circular pipe } \\
\text { propulsion } \\
\text { system }\end{array}$} & $\begin{array}{l}\text { Circular pipe } \\
\text { propulsion } \\
\text { device }\end{array}$ & $\begin{array}{l}\text { - Load capacity : } 500 \mathrm{~kg} . \mathrm{f} \\
\text { - Ram stroke : 0 300 mm } \\
\text { - Load Cell : } 1000 \mathrm{~kg}\end{array}$ \\
\hline & $\begin{array}{l}\text { Circular pipe } \\
\text { control } \\
\text { system }\end{array}$ & $\begin{array}{l}\text { - Displacement control, speed control, } \\
\text { load control } \\
\text { - Real-time graph print-out function }\end{array}$ \\
\hline \multicolumn{2}{|c|}{ Acrylic front panel } & Sand loss prevention \\
\hline \multicolumn{2}{|c|}{$\begin{array}{c}\text { Model ground production } \\
\text { unit }\end{array}$} & Slotted sand scattering device \\
\hline \multicolumn{2}{|c|}{ Calibration chamber test } & $105 \mathrm{~cm} \times 60 \mathrm{~cm} \times 60 \mathrm{~cm}$ \\
\hline \multicolumn{2}{|c|}{ Measurement device } & Upper laser displacement system \\
\hline
\end{tabular}

runoff holes and head height corresponding to a relative density of $80 \%$ through several trials and errors. Fig. 2 shows circular pipe propulsion device, which is composed of reaction plate, electronic load cell and control box. The circular pipe propulsion device was designed to measure expansion of underground displacement due to the vertical and horizontal displacement using a laser displacement meter installed in the upper part of the calibration chamber test that can measure the uplift and settlement results accurately at the speed of $50 \mathrm{~mm} / \mathrm{min}$ as in Fig. 3 and 4. Lase sensor measurement system is consist of laser sensor, portable plate and control unit. The system can be measured up to $1 / 1000 \mathrm{~mm}$, moved left/right direction and printed real-time graphs of the test in the field. The specimens of each device are shown in Table 1.

\subsection{Experimental conditions and methods}

In this study, Joomunjin standard soil was used to create model ground. Particle size distribution and basic physical properties were tested to investigate engineering properties of the Joomunjin standard soil used as a sample. The results of particle size distribution and basic property tests are shown in Table 2, and Fig. 5 shows the particle size distribution of standard soil used in the experiment. Test results showed that Joomunjin standard soil has uniform particle size distribution, and it is classified as SP in unified soil classification system. Mechanical properties of sandy soils vary depending on the degree of density, or relative density, and dry unit weight of the most dense and loose status that can be present in the ground should be identified to determine the relative density. To this end, an experiment to determine minimum and maximum dry unit weight of Joomunjin standard soil was carried out. As its results, the minimum dry unit weight was measured at $14.07 \mathrm{kN} / \mathrm{m}^{3}$, and the maximum dry unit weight was measured at $15.87 \mathrm{kN} / \mathrm{m}^{3}$.
Table 2 Properties of Joomunjin standard soil used in creation of the ground

\begin{tabular}{ccc}
\hline Particle size distibution & & Property \\
\hline Maximum diameter (mm) & Dmax & 0.850 (No. 20) \\
\hline Minimum diameter (mm) & Dmin & 0.075 (No. 200) \\
\hline $\begin{array}{c}\text { Percentage of passage weight } \\
10 \% \text { diameter (mm) }\end{array}$ & D10 & 0.41 \\
\hline $\begin{array}{c}\text { Percentage of passage weight } \\
60 \% \text { diameter (mm) }\end{array}$ & D60 & 0.51 \\
\hline Coefficient of uniformity & $\mathrm{Cu}$ & 1.24 \\
\hline Coefficient of curvature & $\mathrm{Cc}$ & 0.97 \\
\hline Maximum void ratio & $\mathrm{emax}$ & 0.869 \\
\hline Minimum void ratio & $\mathrm{emin}$ & 0.657 \\
\hline $\begin{array}{c}\text { Maximum dry unit weight } \\
\left(\mathrm{kN} / \mathrm{m}^{3}\right)\end{array}$ & $\gamma \mathrm{d}$ max & 15.87 \\
\hline $\begin{array}{c}\text { Minimum dry unit weight } \\
\left(\mathrm{kN} / \mathrm{m}^{3}\right)\end{array}$ & $\gamma \mathrm{d}$ min & 14.07 \\
\hline Weight & $\mathrm{Gs}$ & 2.63 \\
\hline Water content (\%) & $\mathrm{w}$ & 0.2 \\
\hline Unified soil classification & & $\mathrm{SP}$ \\
\hline
\end{tabular}

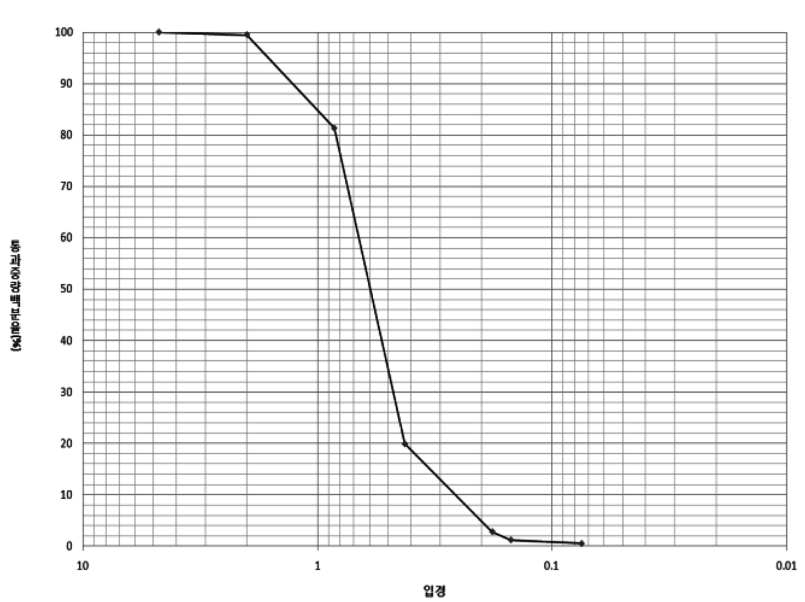

Fig. 5 Particle size distribution curve of Joomunjin standard soil

Table 3 Specification of model pipe

\begin{tabular}{cccc}
\hline Pipe type & Diameter(mm) & Thickness $(\mathrm{mm})$ & Length $(\mathrm{mm})$ \\
\hline Steel pipe & 85 & 1.4 & $600 \mathrm{~mm}$ \\
\hline
\end{tabular}

In a scale model experiment, circular pipes were used to reproduce scale model experiment of method for underground railway crossing. The steel pipe whose size is reduced to $1 / 10$ of pipes used in the field was used, and its specifications are shown in Table 3. For the analysis on the behaviors of track roadbed when steel pipes are injected, 
Table 4 Performed experiment case

\begin{tabular}{ccc}
\hline Type of experiment & Uplift & Settlement \\
\hline Depth of soil cover & $\begin{array}{c}5,10,15,20 \mathrm{~cm} \\
\text { Insertion of pipes }\end{array}$ & $\begin{array}{c}5,10,15,20 \mathrm{~cm} \\
\text { Extraction of internal } \\
\text { block inside the pipes }\end{array}$ \\
\hline
\end{tabular}

the amount of uplift and settlement caused by the deformation of pipes was assumed to be very small.

In this study, an experiment was performed using the depth of soil cover as a variable to analyze behavioral characteristics of track roadbed that occur when steel pipes are injected in case of the construction of a non-excavation method to be carried out for the purpose of creating structures for crossing underground railway. The depth of soil cover was measured by $5,10,15$ and $20 \mathrm{~cm}$, and uplift and settlement by the depth of soil cover was measured. A total of two pipes were injected and excavated respectively. In the case of uplift experiment, injection was made at the control speed of $50 \mathrm{~mm} / \mathrm{min}$ using a propulsion device after fixing internal blocks to the circular propulsion device to prevent leakage of sand. As for settlement experiment, the ground was created after inserting steel pipes up to $30 \mathrm{~mm}$ through a acrylic front panel, and internal blocks inserted inside the pipe were extracted at a rate of $50 \mathrm{~mm} / \mathrm{min}$ using a circular pipe propulsion device. The performance case of this study is summarized in Table 4.

\subsection{Analysis of experiment results}

When pipes are inserted to the ground, the effects caused by the frictional resistance around the inserted pipes acts as a dominant factor for behavioral characteristics of the entire ground. In particular, since ground behavior due to the friction with the upper part of the inserted pipe is directly related to the surface displacement, it has a he impact on the safety and slow-down of railway vehicles. Therefore, an experiment was conducted with friction conditions and surface displacement as variables based on the conditions of the most generalized form by producing an experimental device that models the method of underground railway crossing which is typically being used, and the experiment results were compared and analyzed according to the depth of soil cover.

Fig. 6 shows the amount of settlement by stage. The settlement by stage was simulated by inserting blocks for prevention of sand spill inside the pipes and removing the blocks at the speed of $50 \mathrm{~mm} / \mathrm{min}$ by $30 \mathrm{~mm}$ interval. There was $30 \mathrm{~cm}$ soil excavation in total. However, since $20 \%$ of volume loss was assumed, an analysis was conducted with a tendency of $6 \mathrm{~cm}$ excavation as shown in the Fig.. It turned out that as the depth of soil cover increases,

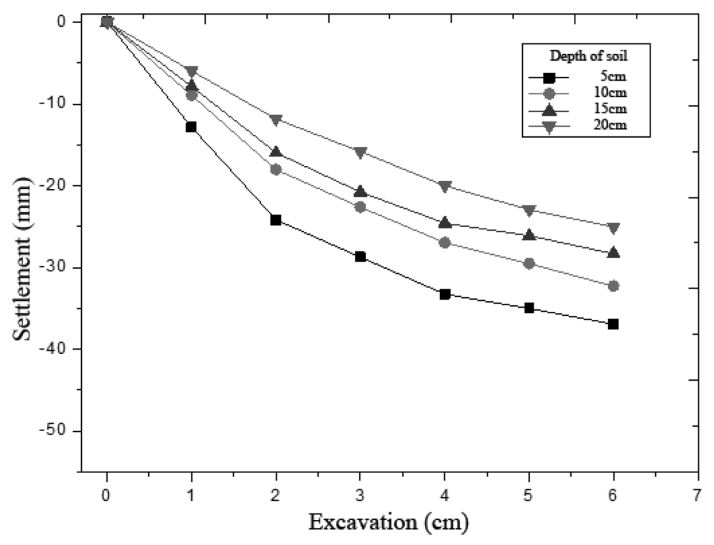

Fig. 6 Settlement amount by stage in case of the first pipe excavation

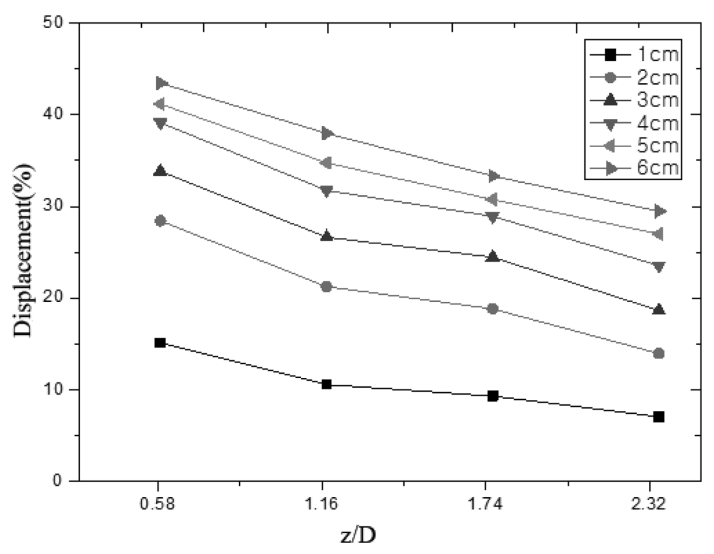

Fig. 7 Settlement ratio by stage in case of the first pipe excavation

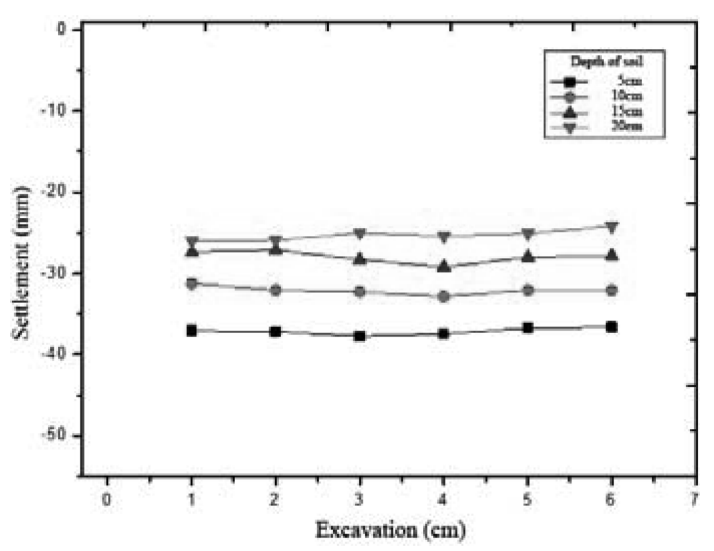

Fig. 8 Settlement amount by stage in case of the second pipe excavation

the amount of settlement decreases, which is due to the load is transferred to the surrounding ground due to arching effects resulting from the heightening of soil cover.

Fig. 7 shows the graph that represents the amount of dis- 


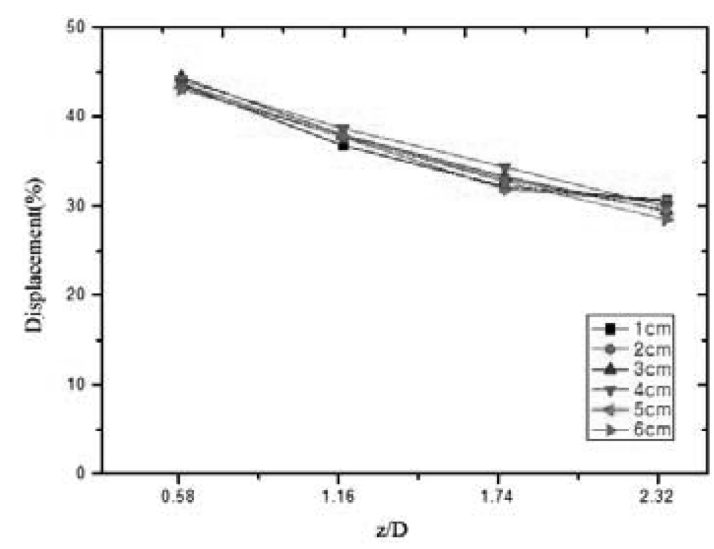

Fig. 9 Settlement ratio by stage in case of the second pipe excavation

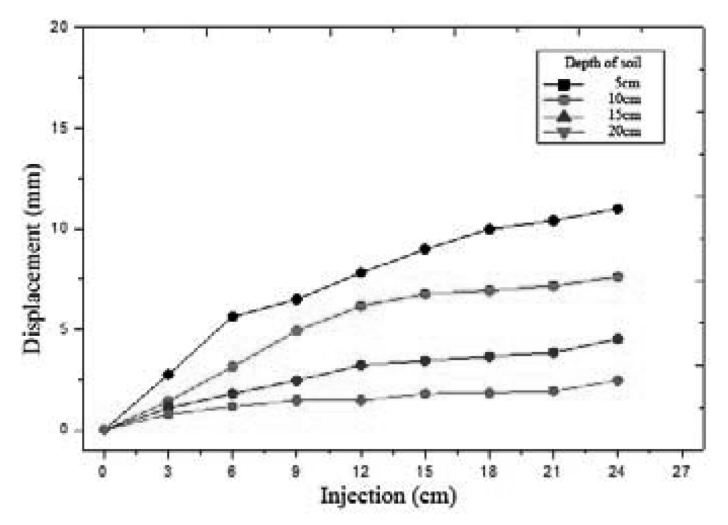

Fig. 10. Uplift rate by stage in case of the first pipe injection

placement in case of inserting the first pipe as the proportion to the diameter of the pipe. I turned out that there is a difference of about 10 to $20 \%$ in settlement amounts between $5 \mathrm{~cm}$ and $20 \mathrm{~cm}$ in the depth of soil cover. The amount of settlement was found to be similar when excavated by $1 \mathrm{~cm}$, but the difference in settlement amounts increased as the excavated amount increased. A lot at the tendency of settlement revealed that the most settlement occurs in the initial excavation of $1 \mathrm{~cm}$, and the settlement amounts decrease gradually as the excavated amounts increase. Analysis results showed that a constant form of settlement appears according to the depth of soil cover, which is attributed to the fact that relaxation zone is formed inside the created sand ground.

Fig. 8 and 9 show the graph that represents a settlement tendency of steel pipes when the first pipe was inserted. The settlement amounts that occur during the first and second excavation were found to show a tendency to converge uniformly. In addition the experiment results showed that the amount of settlement that occurs in case of the first steel pipe insertion is most

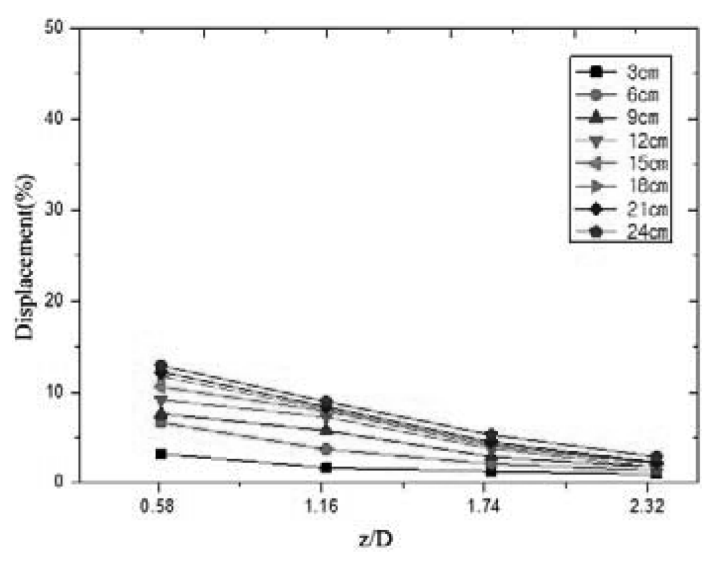

Fig. 11 Proportion of uplift to diameter by stage in case of the first pipe injection

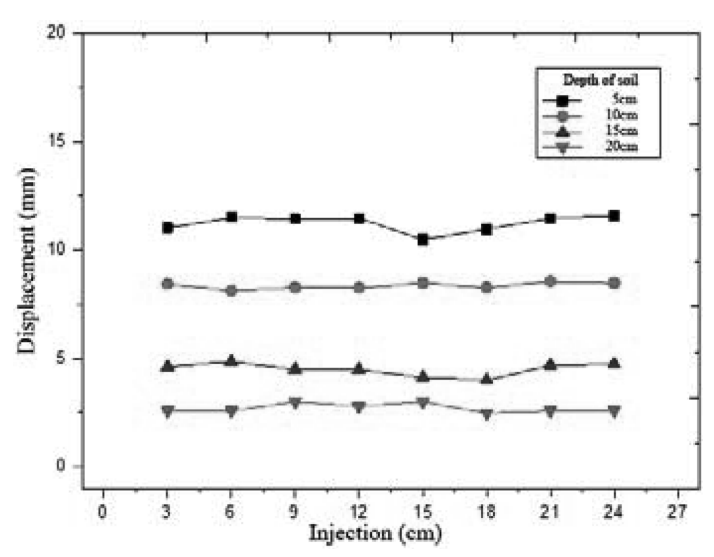

Fig. 12 Uplift rate by stage in case of the second pipe injection

dominant, and steel pipes inserted subsequently do not affect the settlement significantly.

Fig. 10 and 11 show the rate of uplift by stage obtained by scale model experiments. To simulate the uplift rate by stage, an experiment was conducted by fixing blocks for prevention of sand spill inside the pipes and inserting the pipes at the speed of $50 \mathrm{~mm} / \mathrm{min}$ by $30 \mathrm{~mm}$ interval as in case with th e settlement experiment.

Looking at the uplift tendency during the first pipe injection, the uplift increases gradually from the initial insertion, In the case of $5 \mathrm{~cm}$ in the height of soil cover, the uplift occurs from the time of the initial insertion, and the initial uplift tends to decrease as the height of soil cover increases. The most uplift occurred at the initial injection, so that the maximum uplift rate was measured up to about $15 \%$ of the diameter of the pipe, and it showed a tendency to converse after the slight increase from the point of $15 \mathrm{~cm}$, a $50 \%$ point of the pipe in length. It turned out that the higher the height of the soil cover, the smaller the rate 


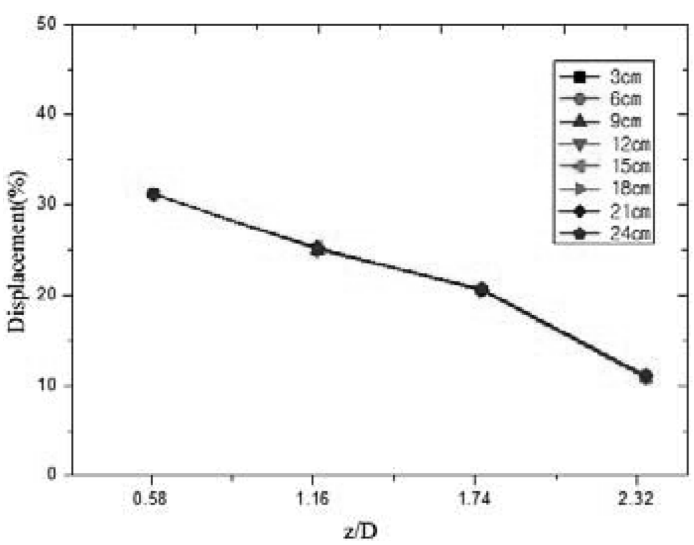

Fig. 13 Proportion of uplift to diameter by stage in case of the second pipe injection

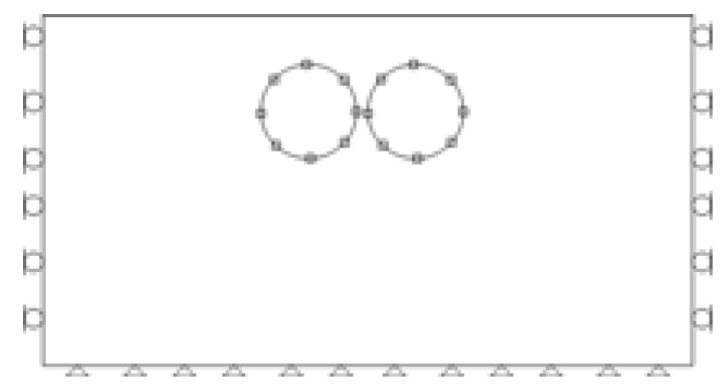

Fig. 14 Boundary condition

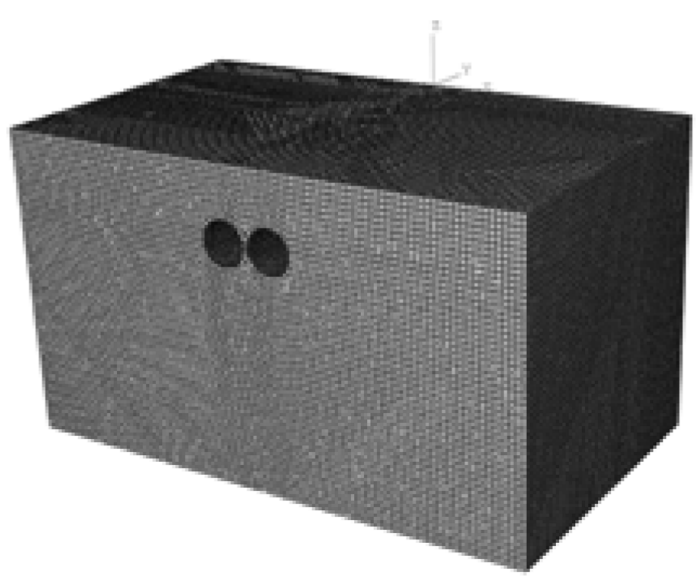

Fig. 15 Finite element mesh used in the analysis

of uplift, and there is a difference of about 10 to $15 \%$ in the uplift rate between points with $5 \mathrm{~cm}$ and $20 \mathrm{~cm}$ in the height of soil cover.

Fig 12 shows the graph that represents the tendency of uplift when the second pipe is inserted. Due to the effect of the first pipe insertion, the upper ground was no longer uplifted, and constant values were measured despite change in the height of soil cover as shown in Fig 3. This
Table 5 Properties of ground and steel pipes

\begin{tabular}{cccccc}
\hline $\begin{array}{c}\text { Materials } \\
\text { applied }\end{array}$ & $\mathrm{c}(\mathrm{kPa})$ & $\phi($ deg. $)$ & $\varphi($ deg. $)$ & $\gamma\left(\mathrm{kN} / \mathrm{m}^{3}\right)$ & $\mathrm{E}(\mathrm{kPa})$ \\
\hline Ground & 1 & 38 & 0.6 & 15 & $1 \times 10^{4}$ \\
\hline Steel pipe & - & - & - & 70 & $2.05 \times 10^{8}$ \\
\hline
\end{tabular}

result leads to the conclusion that the second tube has little effect on the uplift behaviors.

\section{Numerical Comparative Study on Scale Model Experiments}

\subsection{Analysis modeling}

For analysis modeling, we used ABAQUS 6.9-3 (ABAQUS user's manual, 2009), that can simulate the non-linearity of the ground, thereby providing a variety of configuration models and has excellent features to remove and add elements essential for modeling of construction process. In discretization of analysis models, 8-node threedimensional integral elements (C3D8R) were applied in the ground. As for displacement boundary conditions, a roller was applied to the walls, and hinge at the bottom. Tie was applied to steel pipes and ground to prevent deformation from occurring between the steel pipes and the ground. Fig 15 shows finite element mesh applied to the boundary conditions and analysis. In modeling of materials for components, the ground was regarded as a elastoplastic material that complies to Mohr-Coulomb yield criterion and unrelated rules, and it was modeled as plastic behavior. Since steel pipes have little deformation under the same stress condition compared to the ground, it was assumed as linear-elastic behavior. The properties of the ground and steel pipes used in the analysis are shown in Table 5.

\subsection{Analysis conditions and construction process modeling}

The equilibrium status was implemented by applying the initial stress to models to be analyzed and the weight in Step-1 to simulate behaviors of track roadbed by pipe excavation. The excavation stage of the first pipe was simulated in each stage using a point that the maximum settlement occurs when excavation of the first pipe is simulated in model experiment. Volume loss is the method of estimating the loss through the surface displacement. A concept of volume loss was applied in the cause of numerical simulation. As shown in Fig 16, displacement was applied toward the inside of the pipes using the face of a tunnel as displacement control to apply the volume loss of $1 \%, 2 \%, 3 \%, 4 \%, 5 \%$ and $6 \%$ by each stage. Due 


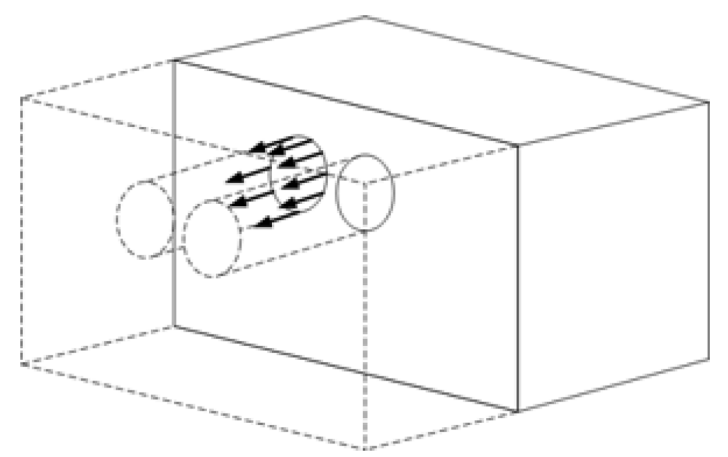

Fig. 16. Simulation of excavation process

Table 6 Progress status by stage

\begin{tabular}{cc}
\hline Step & Progress status \\
\hline Initial & Initial condition applied \\
\hline Step-1 & Dead weight applied \\
\hline Step-2 & Volume loss $1 \%$ \\
\hline Step-3 & Volume loss 2\% \\
\hline Step-4 & Volume loss 3\% \\
\hline Step-5 & Volume loss 4\% \\
\hline Step-6 & Volume loss 5\% \\
\hline Step-7 & Volume loss 6\%
\end{tabular}

to the displacement of a tunnel face, soil is brought to the inside of the steel pipes, resulting in the settlement of the surface. In this study, the form of settlement from the cross-section (perpendicular direction to the pipe direction) where the most settlement occurs was analyzed. The progress status by finite element analysis stage is shown in Table 6.

\subsection{Result analysis and discussion}

Since it is possible to conduct a quantitative comparison of settlement amounts between numerical analysis and model experiment, non-dimensional representation is required to conduct a qualitative comparison. Accordingly, the amount of settlement can be obtained by dividing the maximum settlement values by values in case where the height of soil cover is $5 \mathrm{~cm}$, and volume loss is $6 \%$ in the model experiment, and it was represented as shown in Table 7 . Here, $z / D$ diameter ratio(height of soil cover/steel pipe diameter), $z_{x}=$ the maximum settlement amounts by stage, $z_{\max }=$, and settlement amounts in case of $6 \%$ volume loss was defined. Based on the content of Table 7, results according to volume loss and those according to the height of soil cover/diameter ratio were summarized in Figs. 17 and 18.

The results showed that as volume loss increases from 1 to $6 \%$, settlement ratio of scale numerical analysis and scale model experiments increases. In the initial area of 1 to $2 \%$, sharp slope was formed, but a smaller settlement ratio was measured in the mid-area of 3 to $4 \%$, along with a gentle slope. In the area of 4 to $6 \%$, its ratio showed a tendency to converse. In addition, the diameter ratio increased from 0.59 to 2.36 as in (a) to (d) of Fig.17, the settlement ratio decreased sharply, affecting the height of soil cover and diameter ratio significantly in case of the construction of underground structures such as steel pipe insertion.

Meanwhile, the results according to the diameter ratio of Fig. 18 showed a tendency that as the diameter ratio increases, the settlement ratio increases linearly. As the volume loss increased from 1 to $3 \%$, the slope of diameter ratio and settlement ratio tended to increase. However, the settlement ratio was found to increase with a similar slope with no longer increase in slope in the volume loss of 4 to $6 \%$. As the results of settlement ratio between scale model experiment and numerical analysis, it was found that the result of scale model experiment was greater by 1 to $2 \%$, indicating that numerical results are smaller than the results of scale model experiment, but there was a close similarity in settlement tendency between the two results.

Table 7 Settlement amounts of experiment and numerical analysis

\begin{tabular}{cccccccccc}
\hline \multirow{2}{*}{ Vol loss } & \multicolumn{2}{c}{0.59} & \multicolumn{2}{c}{1.18} & \multicolumn{2}{c}{1.77} & & 2.36 \\
\cline { 2 - 10 } & Exp & FEM & Exp & FEM & Exp & FEM & Exp & FEM \\
\hline $0 \%$ & 0.00 & 0.00 & 0.00 & 0.00 & 0.00 & 0.00 & 0.00 & 0.00 \\
\hline $1 \%$ & 0.335 & 0.246 & 0.302 & 0.208 & 0.229 & 0.162 & 0.180 & 0.131 \\
\hline $2 \%$ & 0.619 & 0.456 & 0.546 & 0.389 & 0.448 & 0.314 & 0.357 & 0.263 \\
\hline $3 \%$ & 0.747 & 0.631 & 0.674 & 0.537 & 0.566 & 0.469 & 0.471 & 0.391 \\
\hline $4 \%$ & 0.878 & 0.775 & 0.804 & 0.658 & 0.718 & 0.613 & 0.628 & 0.518 \\
\hline $5 \%$ & 0.946 & 0.897 & 0.860 & 0.763 & 0.825 & 0.721 & 0.747 & 0.652 \\
\hline $6 \%$ & 1.000 & 1.000 & 0.929 & 0.854 & 0.868 & 0.801 & 0.781 & 0.730 \\
\hline
\end{tabular}




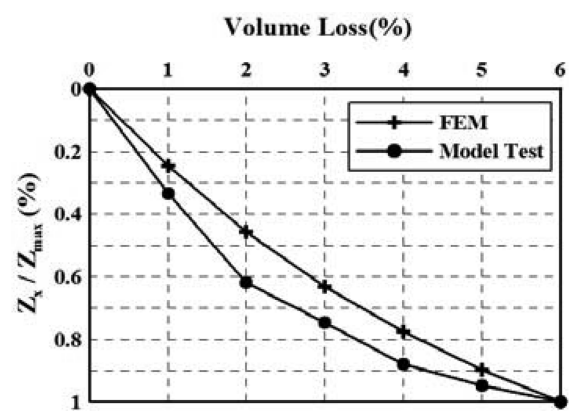

(a) $\mathrm{z} / \mathrm{D}=0.59$

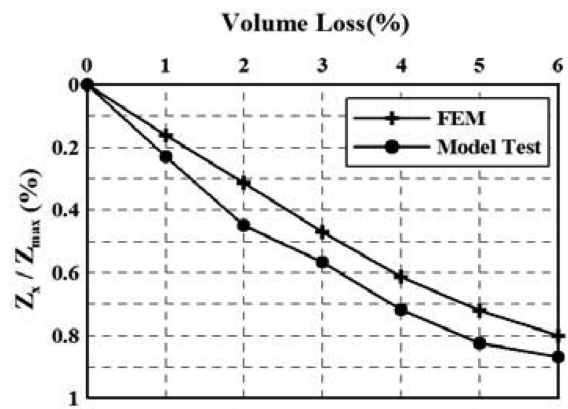

(c) $\mathrm{z} / \mathrm{D}=1.77$

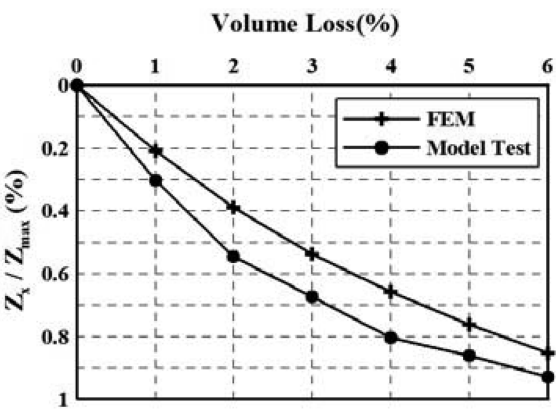

(b) $\mathrm{z} / \mathrm{D}=1.18$

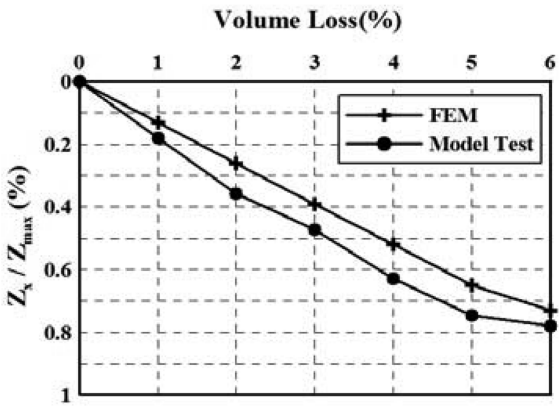

(d) $\mathrm{z} / \mathrm{D}=2.36$

Fig. 17 Results according to volume loss

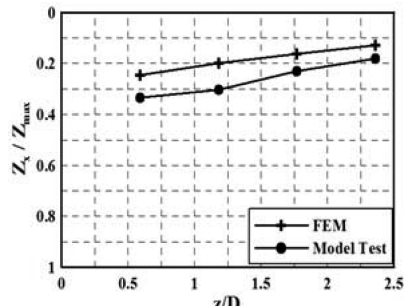

(a) Volume loss $1 \%$

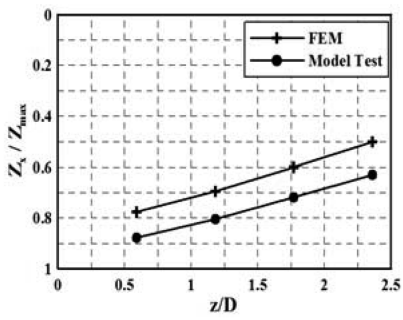

(d) Volume loss $4 \%$

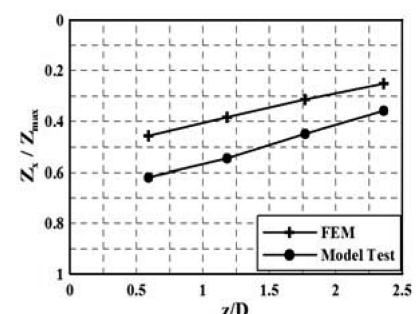

(b) Volume loss $2 \%$

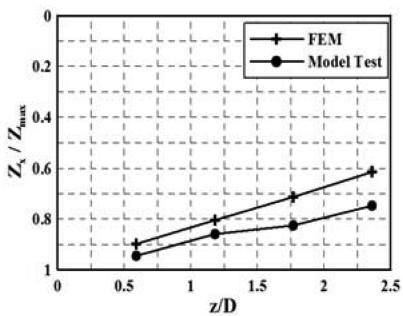

(e) Volume loss $5 \%$

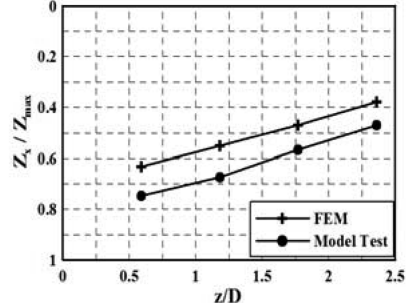

(c) Volume loss $3 \%$

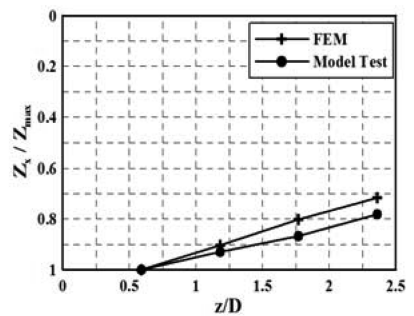

(f) Volume loss $6 \%$

Fig. 18 Results according to diameter ratio

\section{Conclusion}

In this study, we performed scale model experiments and numerical analysis for a comparative analysis to investigate behaviors of track roadbed according to the injection of steel pipes, a representative method for non-excavation underground railway crossing. The results of scale model experiments showed that smaller surface displacement occurred under higher height of the soil cover in the lower part of the injected pipes. In the case of injecting two pipes, when the first pipe was injected, the surface deformation increased linearly in both settlement and uplift experiments, but when the second pipe was injected, the 
A Study on Behavioral Characteristics of Track Roadbed according to Steel Pipe Press-in Excavation......

amount of change turned out to be very small due to the plastic zone and relaxation around the pipe. Since the effect of the first steep pipe is dominant when the pipes are inserted in construction of steel pipe insertion in the field, it is required to construct in consideration of the effects on the settlement and uplift by investigating site situations and soil conditions based on the review of status around the tunnel face. In addition, the results of numerical analysis on the same cross section with the scale model experiment found that the results of investigation into settlement ratio and volume loss was in very good agreement with those obtained by the scale model experiment. Based on the results of experiments and FEM analysis, It will be performed an in-depth study of full-scale section according to construction of underground railway crossing structure.

\section{References}

1. Korea Railroad Research Institute (1999). "A Study on Underground Railroad Crossing Method Selection Criteria".
2. Eric Leca, Animateur, Barry New, General Reporter (2007). "Settlements Induced by Tunneling in Soft Ground", Tunneling and Underground Space Technology 22, pp. 119-149.

3. Yoo Chung-sik, Kim Ju-mi, Kim Seon-bin, and Jeong Hyeyeong. (2006). "GIS-ANN Based Urban Tunnel Design/ Construction Risk Assessment", Journal of Korea Society of Civil Engineers, Vol. 26, No. 1 C, pp. 63-72.

4. Yuk Jeong-hun and Kim Nak-yeong (2004). "Behavioral Characteristics according to Height of Soil Cover of Corrugated Steel Pipe Underground Structures", Journal of Korea Geotechnical Society, Vol. 5, No. 1, pp. 65-73.

5. Eum Ki-young, Choi Chan-yong, and Cheon Jeong-yeon. (2010). "Analysis of Scale Model Uplift and Settlement Experiments according to Shape of Pipes in Non-Excavation Propulsion Method", Journal of Korea Geosynthetics Society, Vol. 9, No. 4, pp. 9-15.

6. Korea Railroad Research Institute (2010). "Research on Safety Evaluation and Establishment of Standards for Method of High- Speed Rail Underground Crossing Structures". 